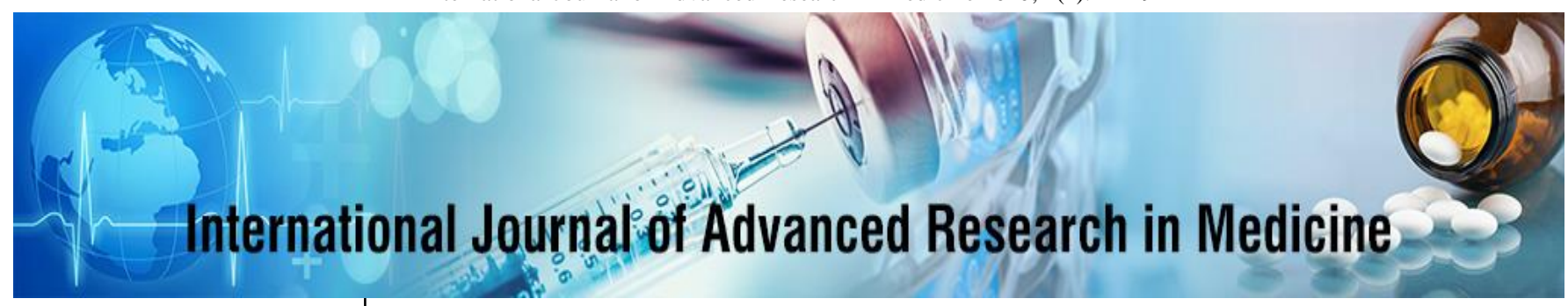

E-ISSN: 2706-9575

P-ISSN: 2706-9567

IJARM 2020; 2(2): 42-49

Received: 01-01-2020

Accepted: 10-02-2020

Sweetha Nayak Nagar MD, Assistant Professor, Department of Microbiology, Srinivas Institute of Medical Sciences and Research Centre, Mangalore, Karnataka, India

Sohan Rodney Bangera Ph.D., Department of Microbiology, Srinivas Institute of Medical Sciences and Research Centre, Srinivas University, Mangalore, Karnataka, India

Dr. Vijaya

MD., Associate Professor, Department of Microbiology, Srinivas Institute of Medical Sciences and Research Centre, Mangalore, Karnataka, India

Corresponding Author: Dr. Vijaya

MD., Associate Professor, Department of Microbiology, Srinivas Institute of Medical Sciences and Research Centre, Mangalore, Karnataka, India

\section{Diagnosis of dermatophytoses: Comparison of mycological techniques}

\author{
Sweetha Nayak Nagar, Sohan Rodney Bangera and Vijaya
}

DOI: https://doi.org/10.22271/27069567.2020.v2.i2a.49

\begin{abstract}
Background: Dermatophytes are a group of closely related fungi that have the capacity to invade keratinized tissue (skin, hair, and nails) of humans and other animals to produce an infection. Infection by this fungi are restricted to the non-living cornified layers as they lack the ability to penetrate the deeper tissues of immuno competent hosts. The great variation in clinical presentation is related to the involved species of fungus, size of the inoculum, involved site and immune status of the host. There are three genera of dermatophyte fungi: Trichophyton, Microsporum and Epidermophyton based on microscopic features. Each genus is characterized by a specific pattern of growth in culture and by the production of macroconidia or microconidia. The Trichophyton species usually infect the skin, hair and nails. Microsporum species infect the skin and hair but not the nails. Epidermophyton species infect the skin as well as nails but not hair. This study was carried out to determine the etiological agents in different forms of dermatophytosis and to compare the various laboratory techniques in the diagnosis of dermatophytosis.

Materials and method: The study was conducted at the department of Microbiology, Srinivas Institute of Medical Sciences and Research Centre, Mangalore, India. 270 specimens obtained from clinically suspected cases of dermatophytoses between December 2017 to December 2019 were included in the study. The samples included skin scraping, nail clipping and plucked hair. The specimen was then subjected to Microscopic examinations like $\mathrm{KOH}, \mathrm{PAS}$, and Calcofluor white stain and Culture on SDA, SDA with Chloramphenicol and DTM.

Results: Male patients infected were found to be $48.88 \%$ and female patients were $51.11 \%$. The most common affected age group was $21-30$ years $(25.1 \%)$. More than $92.59 \%$ of samples were from Tinea unguium. Fungi was demonstrated in $31.85 \%$ of cases, by $\mathrm{KOH}$ wet mount, $41.48 \%$ by calcofluor white stain and $49.62 \%$ by PAS. Out of 135 specimens, 48 specimen yielded growth giving $35.55 \%$ culture positivity on SDA with chloramphenicol.

Conclusion: A success rate of $41.48 \%$ was achieved for detecting fungal elements by microscopy as compared to culture. PAS Stain shows high reliability and sensitivity for detecting onychomycosis compared to $\mathrm{KOH}$ and mycological culture. PAS and the culture combination is superior to combined $\mathrm{KOH}$ and culture for detection of dermatophyte infection. Ninety six isolates were obtained from 270 patients which shows the prevalence of the isolate in and around Mangalore
\end{abstract}

Keywords: Dermatophytes, Potassium Hydroxide mount, Periodic-Acid Schiff Stain, Dermatophyte test medium, Calcoflour stain

\section{Introduction}

Fungal infections are very common in man. Dermatophytosis are the most common types of cutaneous fungal infection seen in man affecting skin, hair, and nail in both developed and developing countries due to advent of immunosuppressive drugs and diseases. Hot and humid climate in the tropical and subtropical countries like India makes dermatophytosis or ringworm as very common superficial fungal infection ${ }^{[1]}$. The dermatophytes are keratinophilic fungus, which causes dermatophytosis by virtue of their unique ability to degrade keratin and thus colonize and invade the skin and its appendages ${ }^{[2]}$. The infections caused by dermatophytes are clinically classified on the basis of the location of the lesion on the body. The name 'ringworm' was based on the worm like appearance of lesion with irregular inflammatory border with some clearing of central area of the lesion. The infection are named according to the body site after the Latin word Tinea ${ }^{[2]}$.

Dermatophytes are generally classified as anthropophilic, zoophilic and geophilic based on their ecology and host preference of which anthropophilic group causes chronic infection, which is difficult to treat ${ }^{[2,3]}$. Geophilic fungi such as M.gypseum are usually transmitted 
from soil source and secondarily transmitted by animal. Human infection caused by M.canis is an important zoophile can involve variety of animal host, but the principle carrier is cat and dog ${ }^{[4]}$. $\mathrm{T}$ verrucosum, $\mathrm{T}$. mentagrophytes are encountered in rural area and it is mostly through the cattle ${ }^{[2]}$. The clinical variation of dermatophytes may resemble some other skin diseases such as pityriasis roseae, eczema, lichen planus. Contact dermatitis may resemble like $\mathrm{T}$. corporis ${ }^{[2]}$.

An understanding of predisposing / aggravating factors can give an idea as how to avert the disease. The Pathogenic potential is dependent on variety of local and systemic factors affecting host resistance to dermatophyte infection. Depression of cellular immunity due to various factors such as malignancy, administration of steroids or immunosuppressive drugs, endocrine disorders such as cushing's disease can lead to atypical generalised invasive dermatophyte infection. Early identification and treatment is essential as once infection is established, the individual become carrier and more susceptible to recurrence ${ }^{[2]}$. Any clinical diagnosis need to be supported by laboratory diagnosis. Culture is a necessary adjunct to direct microscopic examination for definitive identification of etiological agent and in many instances the choice of therapy may be depend upon the specific identification of invasive mould ${ }^{[2]}$. This is especially important in nail and skin infection, often caused by non-dermatophytic filamentous fungi, which are often resistant to usual dosage of the therapy, used for dermatophytic infection ${ }^{[2]}$.

Identification of fungal hyphae in the macerated skin of the web of toes may be difficult due to superadded bacterial infection ${ }^{[3]}$. It is essential to establish the diagnosis of the disease before starting treatment for dermatophytoses, so that specific therapeutic modalities can be monitored during the course of the treatment ${ }^{[5]}$. This study is undertaken to emphasize the correct, rapid and efficient laboratory test in various clinical samples (Skin, Hair and Nail) of clinically suspected cases of Dermatophytoses which will help the dermatologist to initiate appropriate therapy.

\section{Materials and Methods}

The study conducted in the department of Microbiology, Srinivas Institute of Medical Sciences and Research Centre, Mangalore, India. A total of 270 specimens (skin, hair and nail) obtained from clinically suspected cases of dermatophytic infection between December 2017 to December 2019 (two years study) were included for the study.

A detailed history of selected cases was taken in relation to name, age, sex, address, duration of illness and involvement of site. Inclusion Criteria was all specimens collected from suspected cases of dermatophytosis. Exclusion Criteria involved - Other superficial fungal infections, Specimens other than skin, nail \& hair and insufficient material.

The samples include skin scraping, nail clipping and plucked hair. The specimen collected aseptically and transported to the laboratory in a sterile black paper. The specimen then subjected to direct microscopic examination.

\section{Direct microscopic examination}

Specimen collected was subjected to potassium-hydroxide $(\mathrm{KOH})$ wet preparation of various concentrations $(10 \%$, $20 \%$ and $40 \%$ ) depending on the type of clinical specimen for the presence of fungal elements. The fungal elements appear as highly refractile, hyaline septate branching filaments.

The specimens were also subjected to the following microscopic examination -

\section{A. Staining}

1. Calcoflour white stain

2. Periodic acid Schiff (PAS)

\section{All the samples were inoculated onto fungal culture media -}

a) Sabourauds dextrose agar (SDA)

b) Sabourauds dextrose agar with chloramphenicol

For each sample two tubes of SDA will be inoculated and incubated at $25^{\circ} \mathrm{c}$ and $37^{\circ} \mathrm{c}$ respectively for 2- 4 weeks and was observed periodically for growth. If at the end of $4^{\text {th }}$ week no growth is seen it is further incubated for two more weeks. At the end of $6^{\text {th }}$ week no growth is seen it is declared as sterile.

\section{Culture}

After direct microscopic examination, irrespective of demonstration of fungal elements, the specimen was inoculated onto three sets of test tubes, one containing Sabouraud's dextrose agar, Sabouraud's dextrose agar with $0.05 \%$ chloramphenicol, and the other to dermatophyte test medium. Sabouraud's dextrose agar, and Sabouraud's dextrose agar with $0.05 \%$ chloramphenicol was incubated at $28^{\circ} \mathrm{C}$ for upto four weeks and was observed periodically for growth. If no growth was found after six weeks, it was taken as negative for the growth of fungi.

Dermatophyte test medium was incubated at $28{ }^{\circ} \mathrm{C}$ for upto ten days and was observed for colour change. Fungal isolate was identified based on colony morphology, pigmentation, growth rate, slide culture, microscopic examination by Lactophenol cotton blue (LPCB) staining, urease test, hair perforation test and rice grain test.

\section{Macroscopic examination of culture}

The growth on Sabouraud's dextrose agar was examined to study the colony morphology based on following characteristics.

1. Colony characters on obverse: The colour (white, pearl, ivory) and consistency (cottony, velvety, fluffy, suede).

2. Colony characters on the reverse: Presence or absence of pigment, whether diffusing or not.

\section{Microscopic examination of culture}

a. Tease mount/Needle mount: Cultures were examined microscopically by removing a portion of aerial mycelium with a spud and placed on a glass slide into a drop of lactophenol cotton blue and matted mycelial mass was gently teased with a pair of teasing needles and the coverslip was placed on it. The needle mount was observed under low and high power objective of microscope, for the presence of hyphae, macroconidia, microconidia and other accessory structures of vegetative hyphae and the characters of each was noted.

b. Slide culture: Sterile petridish was taken and a piece of filter paper was cut according to the shape of petridish and placed inside the petridish. A ' $\mathrm{V}$ ' tube was placed on the filter paper and a clean glass slide was placed over the ' $\mathrm{V}$ ' tube and 1-2 cover-slips were placed inside. Petridish was 
closed with the lid, wrapped with paper and sterilized using hot air oven.

Procedure: Blocks of (1 x 2 cms) Sabouraud's dextrose agar and corn meal agar were cut using sterile scalpel blade. One such block from both was transferred on to glass slide supported on ' $\mathrm{V}$ ' tube in a petridish. Corners of the agar block were inoculated with the fungal colony using spud. A cover-slip was placed on surface of agar block using sterile forceps. Little amount of sterile distilled water was added to the petridish and the lid closed and incubated at room temperature. After each day the slide was taken out of petridish and examined under microscope without disturbing the cover-slip. When the sporulation was well evident, cover-slip was carefully removed from the agar block and placed on a drop of lactophenol cotton blue stain taken on a separate glass slide taking care to avoid trapping of air bubbles. One or two drops of lactophenol cotton blue were placed on the slide with fungal growth and cover-slip placed on it. Both the slides were examined under microscope. Character of hyphae, size, shape and arrangement of macroconidia, microconidia and other accessory vegetative structures were studied.

1. Urease test: This test is to differentiate between $T$. mentagrophytes and T. rubrum. Christensen's urea agar slant was inoculated with the test fungus. T. mentagrophytes demonstrated the urease activity usually within seven days changing the colour of the medium to pink. T. rubrum isolates were negative for urease test.

2. Hair perforation test: It is used in differentiating $T$. mentagrophytes from $\mathrm{T}$. rubrum. A filter paper disk (approximately $90 \mathrm{~mm}$ in diameter) was placed into the bottom of the sterile petridish and $10-15 \mathrm{ml}$ of sterile distilled water was added to it. Infants hair sterilized by autoclave was then placed on the filter paper. One percent yeast extract was added to it and the test fungus was inoculated on the hair strands. The petridish was incubated at room temperature and hair strands were examined weekly for a period of four weeks. The hair strands were examined under high power of microscope for wedge shaped perforations. The isolates of $\mathrm{T}$. mentagrophytes penetrate hair radially and cause wedge shaped perforation. The isolates of T. rubrum, grow on hair without perforation.

3. Rice grain test: This test is used to differentiate M. audouinii from other Microsporum species. Polished rice grain was sterilized in hot air oven in a flask. Rice grain was inoculated with test fungi and incubated at $28^{\circ} \mathrm{C}$ for 7 to 10 days. M. audouinii grew poorly while other species showed growth ${ }^{[3,11,12,21.22]}$.

\section{Results}

The present study included collection of 270 samples from patients suggestive of dermatophytosis, satisfying the inclusion and exclusion criteria.

Table 1: Gender distribution $(\mathrm{n}=270)$

\begin{tabular}{|c|c|c|}
\hline Sex & No & Percentage \\
\hline Male & 132 & 48.88 \\
\hline Female & 138 & 51.11 \\
\hline
\end{tabular}

Among 270 patients $132(48.88 \%)$ were males and 69
$(51.11 \%)$ were females.

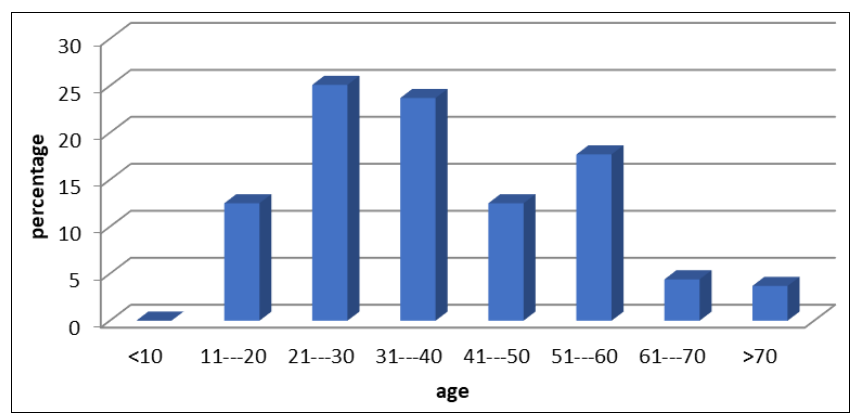

Fig 1: Age distribution of patients

The age group below 50 years accounted for $73.8 \%$ of patients. Whereas, the age group above 50yrs accounted for $26.2 \%$ of the patients. Among those below 50 years, the age group between $21-30$ showed predominance $(25.1 \%)$. Females were majority in number (24) in the age group between $21-30$ when compared to males (10).

Table 2: Number of specimens from different sites of collection

\begin{tabular}{|c|c|c|c|c|c|c|}
\hline \multirow{2}{*}{ Total no. of specimens } & \multicolumn{2}{|c|}{ SKIN } & \multicolumn{2}{c|}{ NAIL } & \multicolumn{2}{c|}{ HAIR } \\
\cline { 2 - 7 } & Male & Female & Male & Female & Male & Female \\
\hline & 8 & 10 & 122 & 128 & 2 & 0 \\
\hline 270 & $18(6.6 \%)$ & $250(92.5 \%)$ & $2(0.9 \%)$ \\
\hline
\end{tabular}

Table 3: Distribution of cases

\begin{tabular}{|c|c|c|c|}
\hline Clinical Types & Number of case & Male & Female \\
\hline T. corporis & $10(3.70 \%)$ & $2(1.5 \%)$ & $8(5.71 \%)$ \\
\hline T. unguium & $250(92.5 \%)$ & $122(93.8 \%)$ & $128(91.4 \%)$ \\
\hline T. cruris & $4(1.48 \%)$ & $0(0 \%)$ & $4(2.85 \%)$ \\
\hline T. capitis & $2(0.74 \%)$ & $2(1.5 \%)$ & $0(0)$ \\
\hline T. barbae & $4(1.48 \%)$ & $4(3.07 \%)$ & $0(0)$ \\
\hline Total & 270 & $65(48.1 \%)$ & $140(51.85 \%)$ \\
\hline
\end{tabular}

Table 4: KOH wet mount screening $(n=135)$

\begin{tabular}{|c|c|c|c|c|}
\hline \multirow{2}{*}{ KOH } & \multicolumn{2}{|c|}{ Positive } & \multicolumn{2}{c|}{ Negative } \\
\cline { 2 - 5 } & Male & Female & Male & Female \\
\cline { 2 - 4 } & $50(58.13 \%)$ & $36(41.86 \%)$ & $82(44.56 \%)$ & $102(55.43 \%)$ \\
\hline Total & \multicolumn{2}{|c|}{$86(31.85 \%)$} & \multicolumn{2}{c}{$184(68.14 \%)$} \\
\hline
\end{tabular}

Table 5: Sample distribution of screened positive cases.

\begin{tabular}{|c|c|c|}
\hline Sample & KOH positive $(\mathbf{n}=43)$ & Percentage \\
\hline Nail $(250)$ & 74 & $29.6 \%$ \\
\hline Skin(18) & 10 & $55.55 \%$ \\
\hline Hair (2) & 2 & $100 \%$ \\
\hline
\end{tabular}

Table 6: Clinical presentation of $\mathrm{KOH}$ positive cases

\begin{tabular}{|c|c|c|}
\hline Clinical presentation & No & KOH positive $(\mathbf{n}=\mathbf{8 6})$ \\
\hline T. corporis & 10 & 6 \\
\hline T. unguium & 250 & 74 \\
\hline T. cruris & 4 & 2 \\
\hline T. capitis & 2 & 2 \\
\hline T. barbae & 4 & 2 \\
\hline
\end{tabular}

Table 7: Outcome of Calcofluor white staining $(n=270)$

\begin{tabular}{|c|c|c|c|c|}
\hline \multirow{2}{*}{ Calcofluor white stain } & \multicolumn{2}{|c|}{ Positive } & \multicolumn{2}{c|}{ Negative } \\
\cline { 2 - 5 } & Male & Female & Male & Female \\
\cline { 2 - 5 } & 58 & 54 & 74 & 84 \\
\hline Total & \multicolumn{2}{|c|}{$112 / 270(41.48 \%)$} & \multicolumn{2}{c|}{$158 / 270(58.51 \%)$} \\
\hline
\end{tabular}


Table 8: Comparison of $\mathrm{KOH}$ with Calcofluor white stain

\begin{tabular}{|c|c|c|c|c|}
\hline \multirow{4}{*}{ Calcofluor white stain } & & \multicolumn{2}{|c|}{ KOH } & \multirow{2}{*}{ Total } \\
\cline { 2 - 5 } & Positive & Negative & \\
\cline { 2 - 5 } & Positive & 84 & 28 & 112 \\
\cline { 2 - 5 } & Negative & 2 & 156 & 158 \\
\hline Total & & 86 & 184 & 270 \\
\hline
\end{tabular}

112 samples were found to be positive for fungal elements by Calcofluor white staining.

Table 9: Comparison of microscopy with clinical presentation

\begin{tabular}{|c|c|c|c|}
\hline $\begin{array}{c}\text { Clinical } \\
\text { presentation }\end{array}$ & No & $\begin{array}{c}\text { KOH positive } \\
(\mathbf{n = 8 6})\end{array}$ & $\begin{array}{c}\text { Calcofluor white } \\
\text { stain(n=112) }\end{array}$ \\
\hline T. corporis & 10 & 6 & 4 \\
\hline T. unguium & 250 & 74 & 100 \\
\hline T. cruris & 4 & 2 & 2 \\
\hline T. capitis & 2 & 2 & 2 \\
\hline T. barbae & 4 & 2 & 4 \\
\hline
\end{tabular}

Table 10: Outcome of PAS Staining

\begin{tabular}{|c|c|c|c|c|}
\hline \multirow{2}{*}{ PAS (n=125) } & \multicolumn{2}{|c|}{ Positive } & \multicolumn{2}{c|}{ Negative } \\
\cline { 2 - 5 } & Male & Female & Male & Female \\
\cline { 2 - 5 } & 66 & 54 & 68 & 62 \\
\hline Total & \multicolumn{2}{|c|}{$120(48 \%)$} & \multicolumn{2}{c|}{$130(52 \%)$} \\
\hline
\end{tabular}

* PAS was prepared only on nail sample.

PAS staining was done only on nail sample (250). Seventy four samples were positive for fungal elements by $\mathrm{KOH}$ screening method whereas, 120 samples were positive for fungal elements by PAS staining method.

Table 11: Result of fungal culture on SDA with Chloramphenicol

\begin{tabular}{|c|c|c|}
\hline Male & Female & Total \\
\hline 38 & 58 & $96(35.55 \%)$ \\
\hline
\end{tabular}

Out of 270 specimens inoculated on SDA with Chloramphenicol, 96 showed growth after varied period of incubation.

Table 12: Distribution of fungi

\begin{tabular}{|c|c|c|c|}
\hline $\begin{array}{c}\text { Total no. } \\
\text { of cases }\end{array}$ & $\begin{array}{c}\text { No. of } \\
\text { dermatophytoses } \\
\text { isolated }\end{array}$ & Other fungus isolates & No growth \\
\hline 270 & 10 & 86 & 174 \\
\hline & $3.71 \%$ & $31.85 \%$ & $64.44 \%$ \\
\hline
\end{tabular}

Table 13: Comparison of SDA with Chloramphenicol with DTM

\begin{tabular}{|c|c|c|c|c|}
\hline & & \multicolumn{2}{|c|}{ DTM } & Total \\
\hline & & Positive & Negative & \\
\hline \multirow{2}{*}{ SDA with chloramphenicol } & Positive & 76 & 20 & 96 \\
\cline { 2 - 5 } & Negative & 0 & 174 & 174 \\
\hline Total & & 76 & 194 & 270 \\
\hline
\end{tabular}

Table 14: Comparison of $\mathrm{KOH}$ wet mount with culture

\begin{tabular}{|c|c|c|c|c|}
\hline \multirow{4}{*}{ KOH } & & \multicolumn{2}{|c|}{ SDA with Chloramphenicol } & Total \\
\cline { 2 - 5 } & & Positive & Negative & \\
\cline { 2 - 5 } & Positive & 36 & 50 & 86 \\
\cline { 2 - 5 } & Negative & 60 & 124 & 184 \\
\hline Total & & 96 & 174 & 270 \\
\hline
\end{tabular}

Table 17: Comparison of microscopy with culture

\begin{tabular}{|c|c|c|c|c|c|}
\hline & KOH & CFW & $*$ PAS & $\begin{array}{c}\text { SDA with } \\
\text { Chloramphenicol }\end{array}$ & DTM \\
\hline Nail (250) & 74 & 96 & 134 & 92 & 72 \\
\hline Skin (18) & 10 & 14 & - & 2 & 2 \\
\hline Hair (2) & 2 & 2 & - & 2 & 2 \\
\hline Total (270) & 86 & 112 & 134 & 96 & 76 \\
\hline
\end{tabular}

* PAS - was performed only on nail sample.

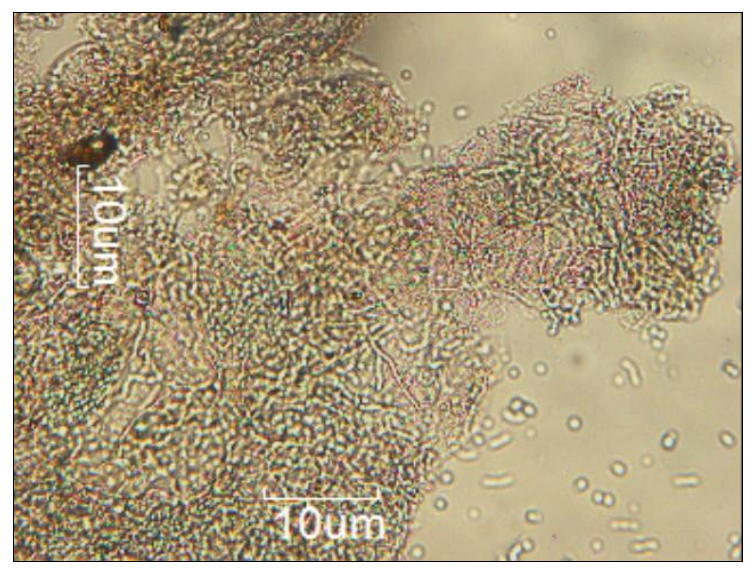

Fig 2: Fungal elements in koh mount

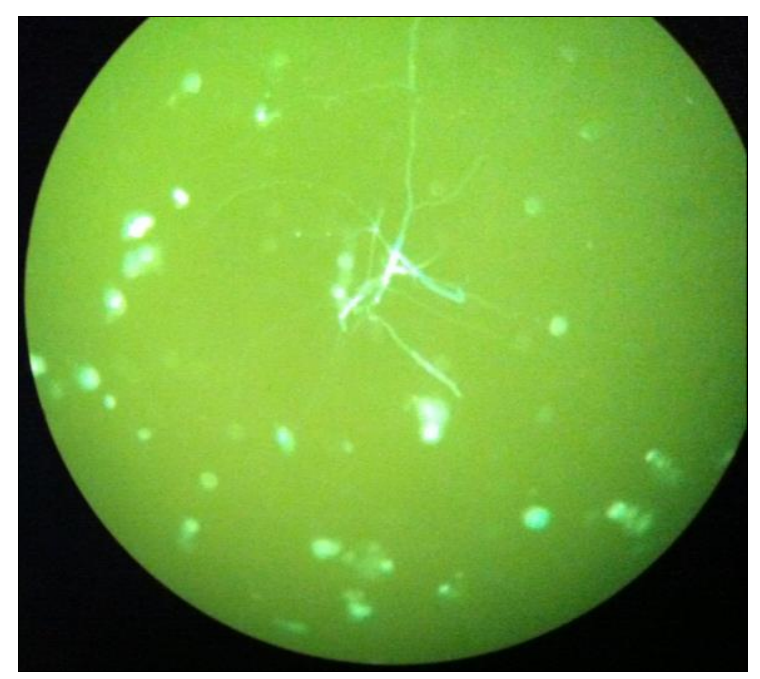

Fig 3: Calcofluor white stain: showing fungal elements at 40x

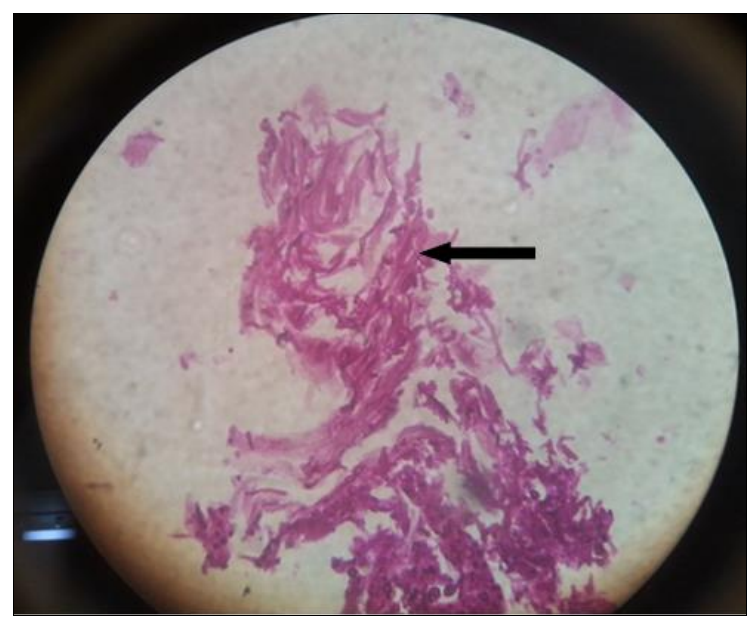

Fig 4: Pas staining showing fungal element in nail tissue 


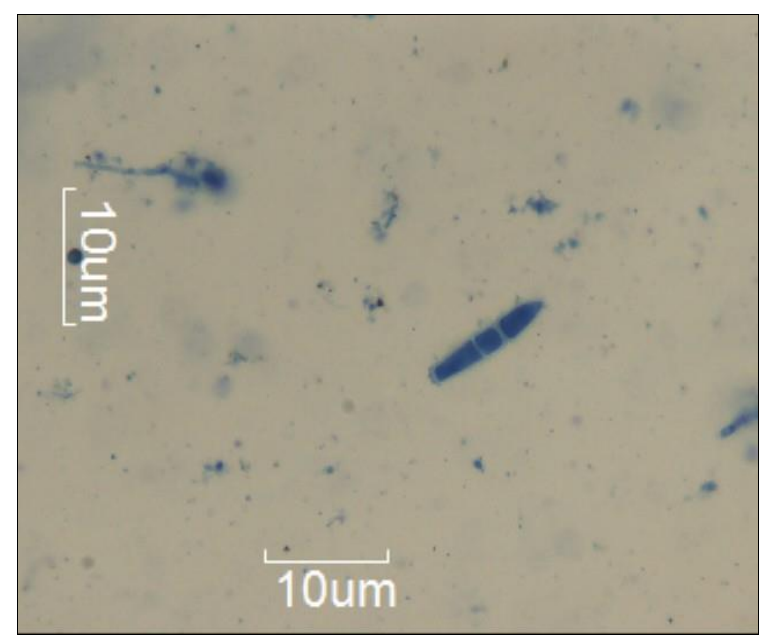

Fig 5: lpcb mount showing macroconidia of t. Mentagrophyte

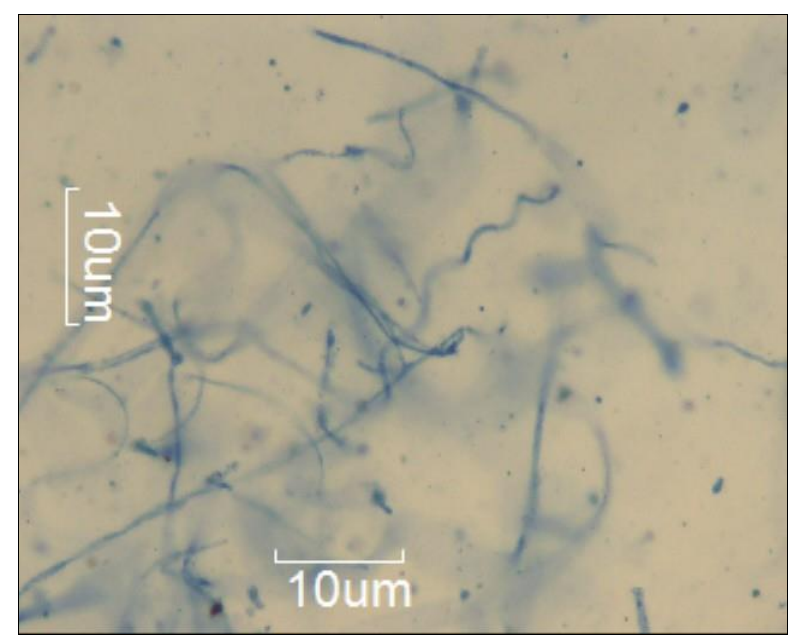

Fig 6: LPCB mount showing spiral hyphae of t. Mentagrophyte

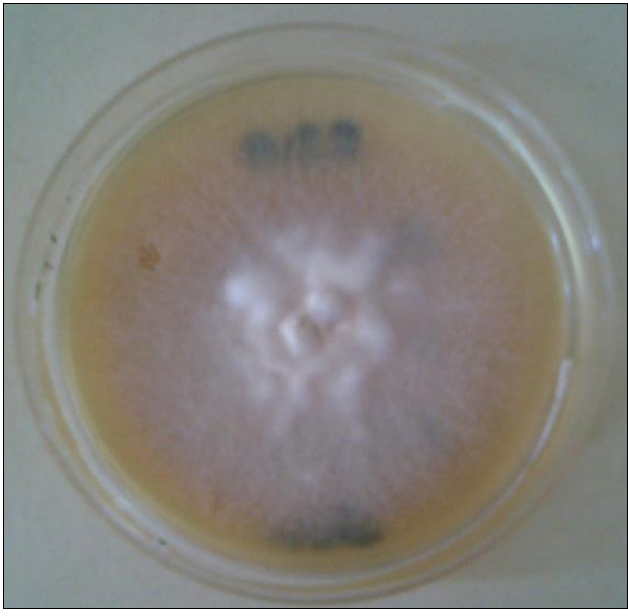

OBVERSE

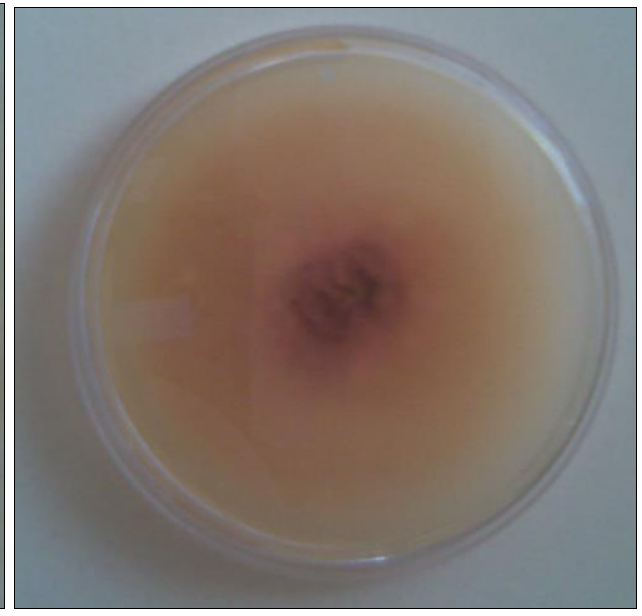

REVERSE

Fig 7: Showing growth of t. Mentagrophyte on SDA

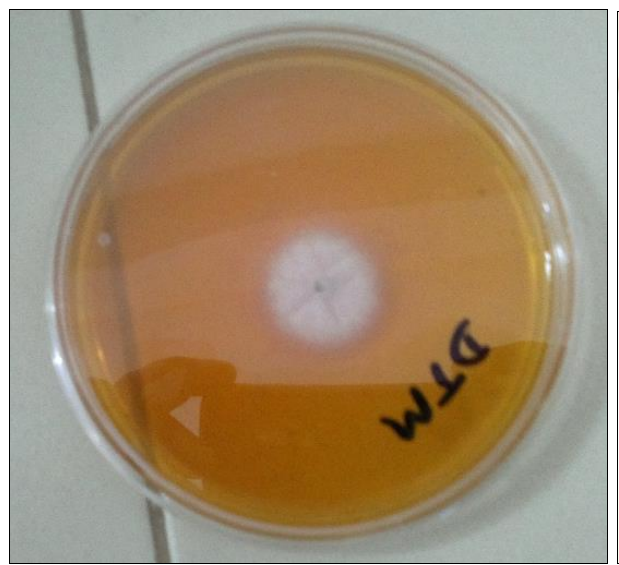

Obverse

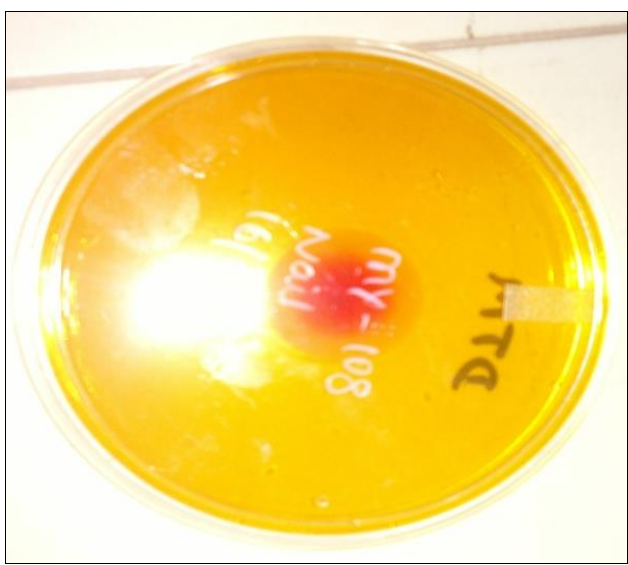

Reverse

Fig 8: showing growth of T. Rubrum on DTM

\section{Discussion}

The worldwide prevalence of dermatophytosis is due to advent of immunosuppressive drugs and diseases, which leads to chronicity, reinfection and spread to the community, thus the need for regular surveillance of the dermatophytosis and its antifungal susceptibility to antifungal agents commonly used for the therapy. The highest incidence of dermatophytosis was among females $120(57.1 \%)$ when compared to males 90 (42.8\%). This could be due to majority of the sample were nail and onychomycosis is more common among females due to their constant contact with water. Climatic conditions like high temperature and humidity have been found to be factors responsible for the high prevalence. Cordeiro RA et. al. ${ }^{[25]}$ and Nada $\mathrm{H}$ et al., ${ }^{[26]}$ reported that dermatophytosis was more common in housewives $(37.7 \%)$ followed by professionals $(28.3 \%)$, manual workers $(13.2 \%)$, students $(13.2 \%)$ and miscellaneous $(7.6 \%)$. The present study shows that dermatophytosis was more common in the age group of 21-30 years $(25.1 \%)$ followed by $31-40$ years $(23.7 \%)$, 
which is comparable with other studies done by Madhuri JT et al., Sen SS et al., Mishra M et al., whereas Veer P has reported that the most common age group affected was 3140 years followed by 41-50 years. The highest incidence in young adults aged 21-30 years may be due to increased physical activity and increased opportunity for exposure.

Majority of the specimen were collected from nails 250 (92.5\%). Among them female predominance was seen. This could be due to the chronicity of onychomycosis and female predominance due to constant contact with water ${ }^{[2,26]}$.

The most common clinical pattern in this study was T.unguim (92.5\%), T.corporis $(3.70 \%)$ followed by T.cruris (1.48\%). The commonest age group affected belonged to the age group of 21-30 years $(25.1 \%)$. Among onychomycosis female predominance was seen showing male to female ratio $0.95: 1$ which is comparable with studies done by Cordeiro $\mathrm{RA}^{25}$ and Nada $\mathrm{H}^{[26]}$. Tinea corporis was the second commonest clinical type (3.70\%). Females (5.71\%) were more commonly affected than males (1.5\%). In Tinea corporis, due to increased itching patients seek medical advice. As the trunk including axilla are usually covered with clothes leading to increased sweating, emission of $\mathrm{CO}_{2}$ (King et al., 1978) creating an environment favourable for dermatophytes ${ }^{[2]}$. Raised carbon dioxide tension is known to facilitate arthroconidial formation and may also aid either adhesion or penetration. Moisture is also important for germination of arthroconidia on keratinocytes ${ }^{[33,34]}$.

Lack of hygiene and overcrowding are some of the factors responsible for higher incidence of dermatophytosis among the house wife and students ${ }^{[35]}$. Tinea cruris was seen only in females. This could be due to both clinical samples of Tinea cruris was obtained from pregnant women, which is a immuno compromised status. Depression of cellular immunity may play an important role in Chronicity ${ }^{[2]}$.

In this study, $\mathrm{KOH}$ positivity was less compared to other studies. It could be due to sampling error, or difficulty in detecting fungal elements in thick nail samples due to inadequate keratin degradation or inability to obtain repeat samples from same patient. $\mathrm{KOH}$ positivity was seen $100 \%$ in $\mathrm{T}$. capitis, $60 \%$ in $\mathrm{T}$. corporis, $50 \%$ in $\mathrm{T}$. cruris and $\mathrm{T}$. barbae and $29.6 \%$ in $\mathrm{T}$. Unguium. Lesser percentage of $\mathrm{KOH}$ sensitivity in $\mathrm{T}$. unguium may be due to thicker nail samples. (As the patient come to hospital in out patient basis. Calcoflour white stain was found to be positive in $56 / 135(41.48 \%)$. Out of 56 patients 29 were male and 27 were female patient. The high positive predictive value of $41.48 \%$ using Calcoflour white stain gives us an alternate staining technique in the diagnosis of fungal elements. Calcoflour white stain picked up 26 samples positive for fungal elements which were negative by $\mathrm{KOH}$ wet mount. Calcofluor binds with chitin and cellulose in fungal cell wall and fluoresces on excitation by long wave UV rays or shortwave visible light ${ }^{[37]}$. The advantage of allowing easier fungal detection with less search time and technical experience (Elders and Roberts). It is technically simple quick and highly reliable to identify fungi even if the observer is relatively inexperienced ${ }^{[3]}$. As conventional $\mathrm{KOH}$ wet mount has been found to be difficult to differentiate hyphae from collagen fibres and other artifacts, Calcofluor White Stain in these situations has found to be far superior in detecting fungi in clinical specimen [3] Calcofluor White Stain turned out to be more sensitive in early detection of fungal elements. The majority of the clinical presentation was T. unguium (40\%). In this study
$48 \%$ were positive for fungal elements by PAS staining and $50.38 \%$ were negative for fungal elements by PAS staining. The positive predictive value of PAS is higher than CWS and $\mathrm{KOH}$ mount. The principle of PAS stain is based on Feulgen Reaction, wherein hydrolysis with hydrochloric acid liberates aldehydes which recolor Schiff's regent. The Polysaccharides of fungi and bacteria are oxidized by periodic acid to form aldehyde groups that yield Magenta coloured compounds with schiff's fuchsin sulphite. The protein and nucleic acids remain unstained. The nuclei stain blue, fungi magenta or deep pink. ${ }^{3}$ PAS has been done only on nail samples to determine efficiency of the stain in detecting fungal elements, in comparison with $\mathrm{KOH}$ and CWS ${ }^{[2]}$.

PAS staining was done only on nail sample. Seventy-four samples were positive for fungal elements by $\mathrm{KOH}$ screening method. Whereas, 120 samples were positive for fungal elements by PAS staining method. This suggests that PAS staining is valuable tool in the diagnosis of onychomycosis. culture positivity on Sabouraud Dextrose Agar was 35.55\%.Lower isolation rate on SDA could be due to following reasons like bacterial contamination, inappropriate sample collection, no repeat sample from patients and contamination with other moulds.

In literature the most common causative agent isolated from onychomycosis are dermatophytes. In India, the isolation rate varies from $70 \%$ to $82.5 \%$ as reported by Patwardhan et.al ${ }^{34}$ and Adhikari et al. ${ }^{[40]}$ from Aurangabad and Sikkim respectively. Garg A et al. in Bhopal and Gupta et al. in Ontario is noted a prevalence of $23 \%$ and $6.86 \%$ respectively ${ }^{[41,42]}$. The difference in the reported prevalence could possibly be attributed to the geographical and cultural differences. The lower isolation rate in our study could be also due to isolation from suspected cases of dermatophytosis and not a diagnosed case of dermatophytosis.

The high prevalence of non dermatophytic fungi in this study could be possibly due to hot and humid climate in this part. The majority of the samples were nail and maximum cases of onychomycosis is caused by non dermatophytic fungi, which are often present in soil. Garg A et al. ${ }^{[41]}$ reported Aspergillus being the most common causative organism of onychomycosis in his study. The reasons for the reduced isolation rate in DTM could be due to $0.5 \%$ actidion which has inhibitory action over non dermatophytic fungi.

In this study the sensitivity of $\mathrm{KOH}$ in comparison with the gold standard culture method is $41.86 \%$ and specificity is $67.39 \%$. Hernandez et al. ${ }^{[36]}$ showed the sensitivity of $88 \%$ and the specificity of $95 \%$ for $\mathrm{KOH}$ wet mount. Our study nail sample were majority in number. Difficulty in detecting fungal elements in thick nail samples due to inadequate keratin degradation may be one of the reason for less $\mathrm{KOH}$ positive reports.

\section{References}

1. Singh S, Beena PM. Comparative study of Different Microscopic Technique and Culture media for isolation of Dermatophytes. Indian J Med. Microbiol. 2003; 21(1):21-24.

2. Aravind A, Padhye, Richard CS. Topley and Wilson's Microbiology and microbial infections. $10^{\text {th }}$ ed. Atlanta: Edward Arnold; Chapter 13, The Dermatophytes, 2005, 220-241. 
3. Jagdish Chander. Text Book of Medical Mycology. $3^{\text {rd }}$ ed. New Delhi: Mehta publishers; Chapter 10, Dermatophytoses, 2009, 122-146.

4. Aravind A. Padhye, Richard CS. Topley and Wilson's Microbiology and microbial infections. $10^{\text {th }}$ ed. Place: Publisher; year. Antifungal Agents and Antifungal Susceptiblity Testing, 163-172.

5. Shenoy MM, Theerthanath S, Karnaker VK, Girisha BS, Krishna Prasad MS, Pinto J. Comparision of Potassium hydroxide mount and mycological culture with histopathologic examination using periodic acid schiff staining of nail clippings in the diagnosis of onychomycosis. Indian J Dermatol venereal leprol. 2008; 74:226-230.

6. Rippon JW. Text book of medical Mycology. $2^{\text {nd }}$ ed. Phila-delphia: WB Saunders; chapter 8, Dermatophytosis and Dermatomycosis, 1988, 154-241.

7. Kwon Chung KJ, Bennet JE. Medical mycology. 2nd ed. Philadelphia, London: Lea and Febiger; Chapter 23, Phaeohyphomycosis, 1992, 620-677.

8. Standring S, Collin P, Borley NR, Crossman AR, Johnson david. Gray's Anatomy-The anatomical basis of clinical practice. $40^{\text {th }}$ ed.London: Churchill Livingstone; Section 1-chapter 7, skin and its appendages, 2008, 145-164.

9. Brasch J, zaldua M, Doniec M, Mertens J, Wellbrock M. Enzyme Patterns of Dermatophes Mycoses. 1994; 37(1-2):11-16.

10. Joya Shree, Nath Barbhuiya, Sankar Kumar Das, Arghyaprasun Ghosh, Sunil kumar Dey, Aparna Lahiri. Mycological Study of Superficial Fungal Infection in Children in an Urban Clinic in Kolkata. Indian $\mathbf{J}$ dermatol. 2002; 47(4):221-223.

11. Collee JG, Fraser AG, Marmion BP, Simmons A. Mackie and McCartney Practical Medical Microbiology. $14 \mathrm{t}^{\mathrm{h}} \mathrm{ed}$. Edinburgh: Churchill Livingstone. 2006; 41:695-717.

12. Monica Cheesbrough. District laboratory practice in tropical countries. Part 2. United Kingdom: Cambridge University Press; Fungal Pathogens, 7.18.38 Dermatophytes, 2000, 235-238.

13. Koneman EW, Allen SD, Janda WM, Schreckenberger PC, Winn WC, Woods Gail GW. Procop. Color Atlas and Textbook of Diagnostic Microbiology. $6^{\text {th }}$ ed. Philadelphia: Lippincott- Williams and Wilkins Publishers; Chapter 21, Identification of the Dermatophytes, 2006, 1187-1192

14. Isenberg HD. Essential procedures for clinical microbiology. 4th ed. Washington: American Society of Microbiology; Chapter 54, Dermatophytes, 1998, 11821184.

15. Weissfeld AS, Sahm DF, Forbes BA. Bailey and

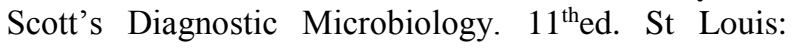
Mosby; Chapter 53, Laboratory methods in basic mycology, 2002, 747-75.

16. Salkin FI, Araind A, Padhye ME, Kemna. A New Medium for presumptive Identification of Dermatophytes. J Clin. Microbiol. 1997; 35(10):26602662.

17. Sally Gromadzki, Rama Ramani, Vishnu Chaturvedi. Evalution of New medium for identification of Dermatophytes and Primary Dimorphic Pathogen. J.Clin. Microbiol. 2003; 41(1):467-468.

18. Weinberg JM, Koestenblatt EK, Turtorie WD, Tishler
HR, Lily Najarian. Comparison of Diagnostic Mehtod in the Evalution of Onychomycosis. J Am. Acad. Dermatol. 2003; 49(2):193-7.

19. Trichohyton Agars 1-7. 2003 Difco $^{\text {TM }} \&$ BBL $^{\text {TM }}$ Manual, 2nd Edition

20. Jagdish Chander. Text Book of Medical Mycology. $3^{\text {rd }}$ ed. New Delhi: Mehta publishers; Appendix A-C, Fungal culture media -Conventional mycological techniques, 2009, 508-530.

21. Kannan P, Janaki C, Selvi GS. Prevalence of dermatophytes and other fungal agents isolated from clinical samples. Indian J Med Microbiol. 2006; 24(3):212-215.

22. Kumar AG, Lakshmi N. Tinea capitis in Tirupati. Indian J Pathol. Microbiol. 1990; 33(4):360-3.

23. Grover C, Arora P, Manchanda V. Tinea capitis in pediatric population: A study from north India. Indian $\mathrm{J}$ Dermatol Venereol Leprol. 2010; 76(5):527-32.

24. Davise H. Larone. Medically important fungi- a guide to identification. $4^{\text {th }}$ ed. Washington DC: ASN press; Dermatophytes part 2, 2002, 229-253.

25. Cordeiro RA, Medrano DJA, Rocha MFG, Monteiro AJ, Meireles TEF, Sidrim JJC et al. Onychomycosis in Ceara (North-east Brazil). Mem Inst Oswaldo Cruz Rio de Janeiro. 2005; 100:1315.

26. Nada H, Allah SS, Mokhtar M. Yeast infections as a cause of nail disease in the Western province of Saudi Arabia. Egypt J Med Lab Sci. 2005; 14:36-56.

27. Karmakar S, Kalla G, Joshi KR. Dermatophytosis in a desert district of Western Rajasthan. Indian J Dermatol Venereol Leprol. 1995; 61:280-3.

28. Veer P, Patwardhan NS, Danle AS. Study of onychomycosis: Prevailing fungi and pattern of infection. Indian J Med Microbiol. 2007; 25:53-6.

29. Sen SS, Rasul ES. Dermatophytosis in Assam. Indian J Med Microbiol. 2006; 24:77-78.

30. Singh S, Beena PM. Profile of dermatophyte infections in Baroda. Indian J Dermatol Venereol Leprol. 2003; 69(4):281-283.

31. Madhuri JT, Rama RGR, Joga LD, Ratna KG. Onychomycosis: A significant medical problem. Indian J Dermatol Venereol Leprol. 2002; 68(6):326-329.

32. Bokhari MA et al. Study of onychomycosis. International J Dermatol. 1999; 38(8):591-595.

33. Rook's, Tony Burns, Christopher Griffiths. Text Book of Dermatology 2. $7^{\text {th }}$ ed. Massachusetts: Blackwell science; Chapter 31, Mycology, 2004; 31(19):31-54.

34. Patwardhan N, Dave R. Indian Journal of Pathology and Microbiology, 1999; 42(4):455-462.

35. Sumana V, Singaracharya MA. Dermatophytosis in Khammam Andrapradesh. Indian J Pathol. Microbiol. Year. 2004; 47(2):287-289.

36. Hernandez, Zanaga T. Superficial Mycoses Comparative Study between type 2 diabetic patient and non-diabetic control group. Invest. Clin. 2005; 46(10):65-74.

37. Weissfeld AS, Sahm DF, Forbes BA. Bailey and Scott's Diagnostic Microbiology. $11^{\text {th }} \mathrm{ed}$. St Louis: Mosby; Diagnostic Microbiology, 2002, 711-797.

38. Alkhayat H, Nourah AS, Elizabeth O Brien, Catherine McCuaig, Kevin Watters. The PAS Stain for routine Diagnosis of Onychomycosis. Baharain Medical bulletein. 2009; 31(2):1-7.

39. Hanif F, Ikram A, Ahmed AS, Malik N. Pattern of 
dermatophytes among dermatological specimens at AFIP, Rawalpindi. Journal of Pakistan Association of Dermatologists. 2012; 22:118-121.

40. Adhikari L, Guptha AD, Pal R, Singh T. Clinicoetiologic correlates of onychomycosis in sikkim. Indian J Pathol Microbiol. 2009; 52:194-7.

41. Garg A, Venkatesh V, Singh M, Pathak KP, Kaushal GP, Agarwal SK. Onychomycosis in Central India: A Clinico-etiologic correlation. Int. J Dermatol. 2004; 43:498-502.

42. Guptha AK, Jain HC, Lynde CW, Watteel GN, Summerbell RC. Prevalence and epidemiology of unsuspected onychomycosis in patients visiting dermatologists office in Ontario, Canada-a multicenter analysis of 2001patients. Int. J Dermatol. 1997; 36:783787.

43. Ali J, Yifru S, Woldeamanuel Y. Prevalence of tinea capitis and the causative agent among school children in Gondar, North West Ethiopia. Ethiop Med J. 2009; 47:261-269.

44. Hamed M.Abdo, Abdel-hamed R.M, Al-Hosiny M.I. $\mathrm{KOH}$ mount versus culture in the diagnosis of tinea capitis. The gulf journal of dermatology and venereology. 2011; 18(1):34-39. 